\title{
An equilibrium profile model for tidal environments*
}

\author{
ANA M. BERNABEU TELLO ${ }^{1}$, RAÚL MEDINA SANTAMARÍA² \\ and CÉSAR VIDAL PASCUAL ${ }^{2}$ \\ ${ }^{1}$ Dpto. de Geociencias Marinas y O. T., Universidad de Vigo, 36200 Vigo. E-mail:bernabeu@uvigo.es \\ 2 Ocean \& Coastal Research Group, Dpto. de Ciencias y Técnicas del Agua y del M. A., Universidad de Cantabria, \\ 39005 Santander.
}

\begin{abstract}
SUMMARY: During a full tidal cycle, the beach profile is exposed to continuously changing hydrodynamical conditions. Consequently, the profile evolves constantly to adapt to these changes. The equilibrium condition on tidal beaches is defined in terms of the relative occurrence of swash, surf zone and shoaling processes. We have assumed that the tidal beach profile is in equilibrium when the net sediment transport along a tidal cycle is zero. In this model the contribution of swash is considered negligible. A simple and easy-to-apply equilibrium profile formulation is proposed. This model is based on the assumption that surf zone processes dominate the profile morphology wherever wave breaking occurs during the tidal cycle. The obtained equilibrium profile is valid from the high tide level to the breaker point at low tide level. The tidal influence on the profile morphology is the lengthening of the surf profile. The higher the tidal range, the longer the surf profile. The model was tested against field and laboratory data, showing reasonable predictions of measured beach profiles.
\end{abstract}

Key words: equilibrium beach profile, tide, wave breaking, wave shoaling.

RESUMEN: Modelo De PERFIL DE EQUILIBRIo PARA PLAYAS CON MAREA. - Durante un ciclo de marea completo, el perfil de playa está expuesto al cambio continuo de las condiciones hidrodinámicas. El perfil evoluciona constantemente para adaptarse a dichos cambios. La condición de equilibrio en playas con marea queda definida en función de la ocurrencia relativa de los procesos de swash, rotura y asomeramiento. El perfil de playa se considera en equilibrio cuando el transporte de sedimento neto a lo largo de un ciclo de marea es nulo. En este modelo, la contribución del swash se considera despreciable. Como resultado, se propone una formulación para el perfil de equilibrio sencilla y de fácil aplicación. El modelo se basa en asumir que los procesos de la zona de rompientes dominan la morfología del perfil en todos aquellos puntos donde se produce rotura durante un ciclo de marea. El perfil de equilibrio obtenido es válido desde el nivel de pleamar hasta el punto de rotura en bajamar. La influencia de la marea en la morfología del perfil es el estiramiento del perfil de rotura. Cuanto mayor es el rango de marea, mayor es la longitud del perfil de rotura. El modelo fue validado con datos de campo y de laboratorio, mostrando una buena predicción de los perfiles medidos.

Palabras clave: perfil de equilibrio, marea, rotura del oleaje, asomeramiento.

\section{INTRODUCTION}

Most of the studies and models on beach morphodynamics developed over the last few decades have focused on microtidal beaches. Consequently, the tidal effect on coastal processes and beach mor-

\footnotetext{
*Received December 19, 2001. Accepted June 27, 2002.
}

phology has received little attention. Somehow, its importance has been unintentionally minimised under the general assumption that wave processes are dominant.

Though meso- and macrotidal beaches form a large proportion of the world beaches, their study has been restricted to particular cases (Wright et al., 1982; Jago and Hardisty, 1984; Horn, 1993). Some 
important advances of these works comprise the determination of waves as the main energy mechanism that modifies the morphology of this type of beach, and the acknowledgment that the tide itself plays a secondary role. Its effect is fundamentally understood as the translation of the different wave processes along the profile: the shoaling and the swash and surf zone processes, to each one of which a time-varying zone of incidence during the tidal cycle is assigned. As Davis and Hayes (1984) pointed out, the beach morphology not only depends on the absolute wave height or tidal range, but on the combination of the two processes. The results obtained by Wright et al. (1982), Jago and Hardisty (1984) and Horn (1993) agree that the shoaling is the dominant process in the low tidal zone, but that in the high tidal zone, the morphodynamics is controlled by swash and surf zone processes. However, these authors attribute different controlling processes to the mid-tidal zone. Masselink (1993) developed a model to simulate the tidal effect on beach morphodynamics, based on the time-share that each point is subjected to the different wave processes along the tidal cycle. However, Masselink and Short (1993) opportunely brought into the discussion the fact that the relative time of occurrence does not determine the scale of the process. The swash and wave breaking processes are more energetic than the shoaling and are more important overall, though they act for a shorter time span on the profile.

In the same way, most of the equilibrium beach profile models (Bruun, 1954; Dean, 1977; Bodge, 1992; Muñoz-Pérez et al., 1999) consider a constant sea level, even when the majority of field data used in their validation belong to tidal beaches. Swain (1989) incorporated the tidal effect in the numerical equilibrium beach profile of Swart (1974) and demonstrated that the tide has a direct influence on the beach profile evolution. Kotvojs and Cowell (1990) found that in beaches with a tidal range greater than the wave height, the Dean profile is not useful for predicting the beach profile.

Bernabeu et al. (2001), Medina et al. (2000) and Bernabeu (1999) have already proposed a two-section equilibrium profile model assuming a constant sea level. Based on this model, the effect of the tide on the beach profile is analysed considering the relative importance of wave processes affecting the profile. The main objective here is to develop a simple and easy-to-apply model to characterise and predict the profile morphology in tidal beaches. For this purpose a general equilibrium profile model valid for micro-, meso- and macrotidal beaches is proposed. Finally, the results are tested for field and laboratory data.

\section{TWO-SECTION EQUILIBRIUM PROFILE MODEL}

Bernabeu (1999) proposed a two-section equilibrium profile based on the different dissipation processes that act on the profile. The action of the turbulence dissipation and the bottom friction dissipation allowed the profile to be divided into a surf and a shoaling profile, treating each section independently. The equilibrium formulation included the energy reflection processes. Ultimately two expressions associated with each section of the profile were developed:

Surf profile $\quad x=\left(\frac{h}{A}\right)^{3 / 2}+\frac{B}{A^{3 / 2}} h^{3}$

Shoaling profile $X=x-x_{0}=\left(\frac{h}{C}\right)^{3 / 2}+\frac{D}{C^{3 / 2}} h^{3}$

where $\mathrm{x}$ is the horizontal distance to the shoreline, $\mathrm{h}$ is the depth and $x_{0}$ is the distance between the shoreline and the beginning of the shoaling profile. The coefficients $\mathrm{A}$ and $\mathrm{C}$ are related to the dissipation processes and the coefficients $\mathrm{B}$ and $\mathrm{D}$ to the energy reflection. Consequently, the coefficients $\mathrm{B}$ and $\mathrm{D}$ tend to zero in dissipative beaches because the reflection phenomenon is negligible. The model expressions (1) and (2) are simplified to the Dean profile.

Figure 1 shows a sketch of the profile divided into two sections joined at the discontinuity point $\left(\mathrm{x}_{\mathrm{r}}, \mathrm{h}_{\mathrm{r}}\right)$, and their characteristic parameters. The discontinuity point location is defined by $\mathrm{x}_{\mathrm{r}}$, the horizontal distance between the beginning of the surf profile and the discontinuity point; and $\mathrm{h}_{\mathrm{r}}$, the discontinuity point depth. This profile point coincides with the breaker point, and the parameter $h_{r}$ is function of the wave height that reaches the beach. The depth $h_{a}$ determines the offshore limit of the model validity, since it considers shallow water linear wave theory.

The validation of the model with measured profiles gave an idea of the morphological information compiled by each coefficient of the model. The coefficients $\mathrm{A}$ and $\mathrm{C}$ are directly proportional to the slope of the upper part of the surf and shoaling profile respectively. The coefficients $\mathrm{B}$ and $\mathrm{D}$ are inversely related to the slope of the lower part of the 


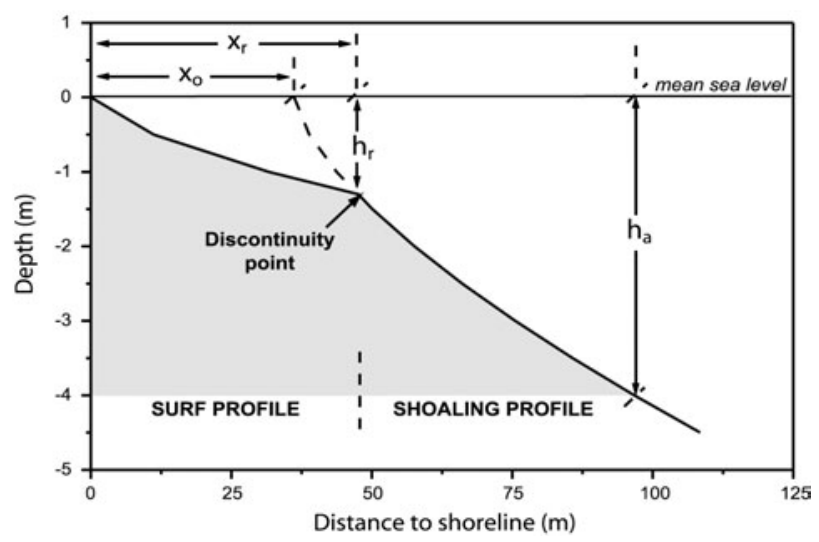

FIG. 1. - Two-section equilibrium profile model and representative parameters (Bernabeu, 1999): $\mathrm{x}_{\mathrm{r}}$ is the horizontal distance between the beginning of the surf profile and the discontinuity point; $h_{r}$ is the discontinuity point depth; $x_{0}$ is the horizontal distance between the beginning of the surf profile and the virtual origin of the shoaling profile over the mean sea level; and $h_{a}$ determines the offshore limit of the model validity.

surf and shoaling profile respectively. The data analysis established that the model coefficients depend on the grain size and the wave climate through the dimensionless fall velocity $\Omega=\mathrm{H} / \mathrm{wT}$, proposed by Dean (1973).

This model has a wide application from reflective to dissipative beaches and includes the different wave processes that affect the beach profile: dissipation and reflection. However, the two-section equilibrium profile is described for a constant sea level. Consequently, this model as it was presented in previous works is not useful in tidal beaches.

\section{DESCRIPTION OF THE MODEL}

Tide generates a constant depth variation at each point of the beach profile. The main effect of these changes is the modification of the hydrodynamic conditions that affect the beach. In a tidal cycle, the location of the swash, surf and shoaling zone varies with time. The intertidal profile is affected in a different way by these processes each 12 or 24 hours. Consequently, the profile is in permanent disequilibrium and evolves constantly to adapt to these changes.

Due to this disequilibrium state, a significant transversal sediment transport occurs along the beach profile. The sediment transport is defined according to the difference between actual energy dissipation and equilibrium dissipation (Kriebel and Dean, 1985):

$$
\mathrm{Q}=\mathrm{K}\left[\mathrm{D}(\mathrm{t})-\mathrm{D}^{*}\right]
$$

where $\mathrm{Q}$ is the sediment transport along the profile, $\mathrm{D}(\mathrm{t})$ is the instantaneous dissipation, $\mathrm{D}^{*}$ is the energy dissipation when the profile reaches the equilibrium situation, and $\mathrm{K}$ is a coefficient. In this situation, the sediment transport follows the two possible tendencies described in Figure 2. When the grains response to the disequilibrium is to move offshore, the slope flattens and the profile shows an erosive situation. When the grains move onshore, the slope becomes steeper and the profile is accumulative.

Considering this disequilibrium state in a tidal beach, a new equilibrium condition is proposed for profiles with tide when the net sediment transport in a tidal cycle is nil. We define the equilibrium tidal beach profile as complying with:

$$
\overline{\mathrm{Q}}=\frac{1}{\mathrm{~T}_{\mathrm{m}}} \int_{0}^{\mathrm{T}_{\mathrm{m}}} \mathrm{Q} \mathrm{dt}=0
$$

where $\overline{\mathrm{Q}}$ is the average sediment transport in a tidal cycle and $\mathrm{T}_{\mathrm{m}}$ is the tidal period. Due to the constant sea level variations, the mean sediment transport is the sum of the transport associated with the different

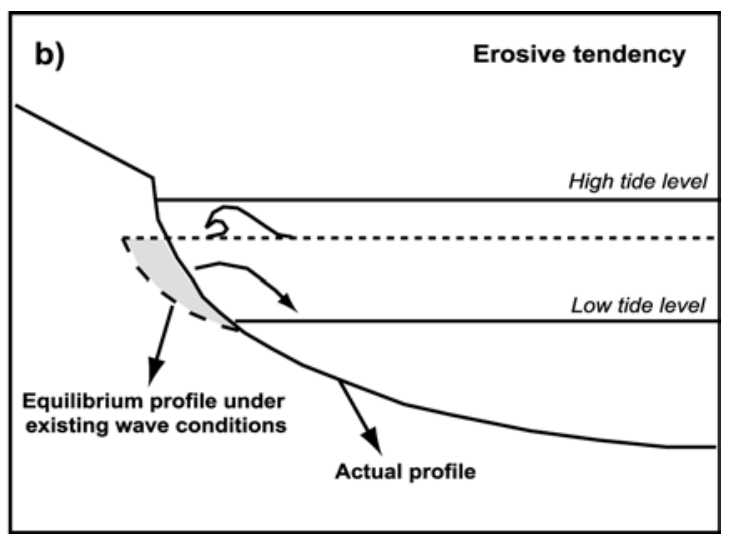

FIG. 2. - Description of the two possible situations of a profile under dynamical variables changing in time: $a$. accumulative tendency; $b$. erosive tendency. 
processes acting on the profile, namely swash, breaking and shoaling. Thus, equation (4) is developed:

$$
\bar{Q}=\frac{1}{T_{m}}\left[\int_{t_{1}}^{t_{2}} Q_{s w} d t+\int_{t_{2}}^{t_{3}} Q_{b} d t+\int_{t_{3}}^{t_{4}} Q_{s} d t\right]=0
$$

where $\mathrm{Q}_{\mathrm{sw}}$ is the transport due to the swash process, $\mathrm{Q}_{\mathrm{b}}$ is the transport associated with wave breaking and $\mathrm{Q}_{\mathrm{s}}$ is related to the wave shoaling. The integral limits represent the time interval during which a given point is under the influence of each dynamic process during the tidal cycle. Substituting equation (3) in (5), the equilibrium condition for a tidal beach is:

$$
\begin{gathered}
\bar{Q}=\frac{1}{T_{m}}\left[\int_{t_{1}}^{t_{2}} K_{s w}\left(D_{s w}-D_{s w}^{*}\right) d t+\right. \\
\left.+\int_{t_{2}}^{t_{3}} K_{b}\left(D_{b}-D_{b}^{*}\right) d t+\int_{t_{3}}^{t_{4}} K_{s}\left(D_{s}-D_{s}^{*}\right) d t\right]=0
\end{gathered}
$$

where $\mathrm{K}_{\mathrm{i}}$ is a proportionality coefficient, $\mathrm{D}_{\mathrm{i}}$ is the actual dissipation and $\mathrm{D}_{\mathrm{i}}^{*}$ is the equilibrium dissipation, where $\mathrm{i}=\mathrm{sw}, \mathrm{b}, \mathrm{s}$. This expression defines the general equilibrium condition for the tidal profile. In the intertidal profile, each point suffers the three processes: swash, surf zone processes and wave shoaling, and the complete expression applies. Offshore the breaker point at low tide level (between $h_{r}$ and $h_{a}$ in Figure 3), the profile is exclusively under shoaling, and therefore the equilibrium condition is reduced to the last term in expression (6). The solution of equation (6) thus describes a two-section equilibrium profile for tidal beaches. Figure 3 shows the proposed equilibrium profile model for tidal beaches.

The main objective of this work is to obtain a general equilibrium profile that is applicable to tidal beaches. This model is useful for the monitoring, management and nourishment of beaches. It may also be easily developed into a practical and predictive tool for coastal processes. The development of a simple and easy-to-apply model has therefore been a self-imposed fundamental constraint in this study.

The swash zone is located between the mean sea level and the uppermost limit of the uprush action. In tidal beaches, this zone runs along the profile during a tidal cycle. Masselink (1993) modelled the relative occurrence of swash, surf and shoaling processes on the beach profile empirically, concluding that the swash process mainly dominates the upper part of the high tide profile. Bagnold (1940) performed a number of laboratory experiments in

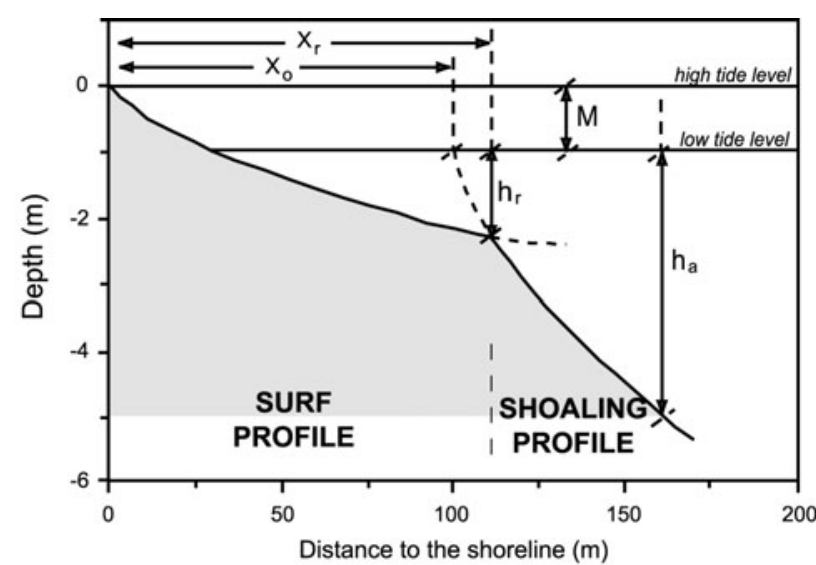

FIG. 3. - Adjustment of the two-section equilibrium beach profile of Bernabeu (1999) to tidal beaches. The beginning of the shoaling profile is displaced with the low tide level. In the analytical formulation the parameter $\mathrm{x}_{\mathrm{o}}$ incorporates the tidal range, $\mathrm{M}$.

which the beachface morphology was initially related to the asymmetry of swash flow due to the infiltration. He also suggested that infiltration is negligible in fine to medium sand beaches. Field observations carried out by Dubois (1972) supported this idea. More recently, Masselink and Li (2001) analysed the role of swash infiltration using a numerical model. They proposed a critical grain size of $1 \mathrm{~mm}$ for the swash to become important in controlling the morphology of the beachface. In beaches with grain sizes smaller than this value, the beachface gradient is controlled by mechanisms related to sediment suspension. Their modelling is today poorly developed (Elfrink and Baldock, 2002), so models of shoreline evolution have so far made slow progress in dealing with the swash zone (Butt and Russell, 2000).

Considering the above, and given the scale and purpose of the proposed model, we understand that the effect of swash is well beyond the scope of this paper, and subsequently we can safely assume that coefficient $\mathrm{K}_{\mathrm{sw}}$ is equal to zero. Then the equilibrium condition, equation (6), can be solely defined in function of the wave breaking and shoaling:

$$
\begin{aligned}
\bar{Q} & =\frac{1}{T_{m}}\left[\int_{t_{2}}^{t_{3}} K_{b}\left(D_{b}-D_{b}^{*}\right) d t+\right. \\
& \left.+\int_{t_{3}}^{t_{4}} K_{s}\left(D_{s}-D_{s}^{*}\right) d t\right]=0
\end{aligned}
$$

Fredsoe and Deigaard (1992) established that the sediment transport associated with breaker waves is one order of magnitude higher than that generated by shoaling waves. This is because of the strong turbulence owing to the wave breaking inside the surf zone. Considering the order of magnitude of each 
term, $\mathrm{K}_{\mathrm{b}} \gg>\mathrm{K}_{\mathrm{s}}$, the equilibrium condition at a given point of the profile affected by wave breaking during the tidal cycle is simplified to:

$$
\bar{Q}=\frac{1}{T_{m}} \int_{t_{2}}^{t_{3}} K_{b}\left(D_{b}-D_{b}^{*}\right) d t=0
$$

This expression defines that the instantaneous dissipation associated with the wave breaking is equal to the equilibrium dissipation, $\mathrm{D}_{\mathrm{b}} \approx \mathrm{D}_{\mathrm{b}}$. This equality coincides with the equilibrium condition for the surf profile at constant sea level. Solving equation (8), the surf profile for tidal beaches takes a similar expression to the Bernabeu (1999) profile in Equation (1).

The equilibrium condition for tidal profiles described in equation (8) assumes that the wave breaking dominates the profile morphology wherever the wave breaking has occurred during the tidal cycle. Consequently, the obtained equilibrium profile, expression (1), is valid between the high tide level and the breaker point at low tide. The final equilibrium state is the maximum erosion position where the accumulation generated during the tidal cycle is swept by wave breaking erosion of the deposited material.

Offshore the breaker point at low tide level, there is no wave breaking $\left(\mathrm{K}_{\mathrm{b}}=0\right)$ and the sediment transport associated with wave shoaling is now significant. The equilibrium condition for the shoaling profile in a tidal beach is:

$$
\overline{\mathrm{Q}}=\frac{1}{\mathrm{~T}_{\mathrm{m}}} \int_{\mathrm{t}_{3}}^{\mathrm{t}_{4}} \mathrm{~K}_{\mathrm{s}}\left(\mathrm{D}_{\mathrm{s}}-\mathrm{D}_{\mathrm{s}}^{*}\right) \mathrm{dt}=0
$$

This formulation determines that $\mathrm{D}_{\mathrm{s}} \approx \mathrm{D}_{\mathrm{s}}^{*}$, coinciding with the equilibrium conditions for the shoaling profile without tide. The shoaling profile in tidal beaches has the same expression as Equation (2).

The two-section equilibrium profile for tidal beaches coincides with the formulation for beaches considering a constant sea level. The coefficients A, B, C and D conserved the previous definition given in Bernabeu (1999). In tidal beaches, the intertidal or surf profile spans from the high tide level to the breaker point at low tide. The larger the tidal range, the longer the surf profile. The main tidal effect on the beach profile morphology is the stretching of the surf profile as a function of the tidal range. The discontinuity point is always submerged below the low tide level at a depth $h_{r}$. The lengthening effect is compiled in the analytical expression obtained to define the parameter $\mathrm{x}_{\mathrm{o}}$ of the equilibrium profile:

$$
\begin{gathered}
x_{0}=\left(\frac{h_{r}+M}{A}\right)^{3 / 2}-\left(\frac{h_{r}}{C}\right)^{3 / 2}+ \\
+\frac{B}{A^{3 / 2}}\left(h_{r}+M\right)^{3}-\frac{D}{C^{3 / 2}} h_{r}^{3}
\end{gathered}
$$

where the horizontal distance between the beginning of the surf profile and the virtual origin of the shoaling profile over the low tide level is a function of the tidal range, $M$.

\section{BASE DATA FOR MODEL TESTING}

Beach profiles of diverse wave climate and tidal range conditions were employed to test the two-section equilibrium profile proposed here. Nine profiles were measured along the Spanish coast (Fig. 4). The profiles of San Lorenzo and Zumaia beaches reflect the discontinuity point associated with high energy conditions. These relict profiles are included in the model analysis, considering that they are related to storm conditions. The measured profiles and the sedimentary characteristics analysed were originally compiled by Gómez-Pina (1995), whilst the wave parameters were taken from R.O.M. (MOPT, 1992) and from the Spanish Grid of Measure and Record of Waves (REMRO). The wave height and period corresponded to the average values of the month preceding the dates in which the profiles were measured. For storm profiles, the highest significant wave height and associated period for the previous six month are considered. The modal tidal data ranged from micro- to macrotidal (Davies, 1964). The wave, tidal and sedimentary parameters are

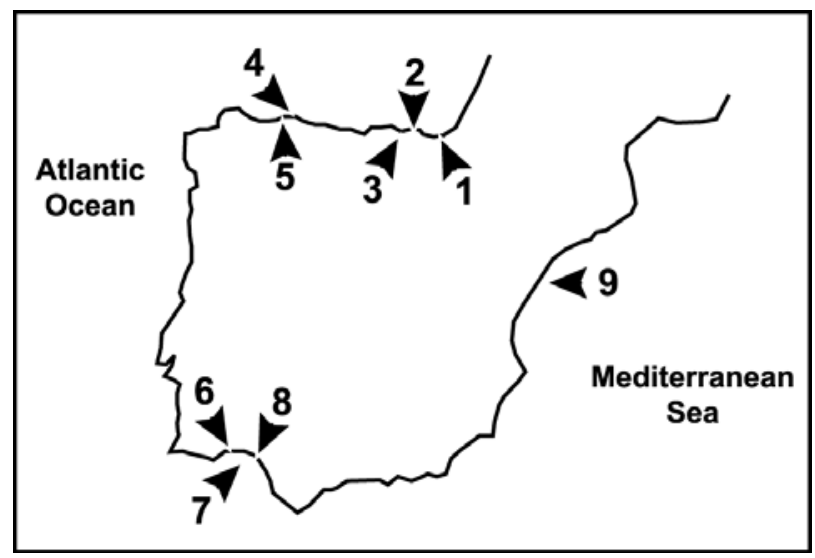

FIG. 4. - Location of the studied beaches along the Spanish coast: 1) Zumaia Beach, 2) Zarautz Beach, 3) Bakio Beach, 4) San Lorenzo Beach, 5) Carranques Beach, 6) La Antilla Beach, 7) Castilla Beach, 8) La Barrosa Beach, 9) El Vendrell Beach. 
TABLE 1. - Wave climate, tidal range and grain size parameters corresponding to the field beach profiles. The symbol (T) refers to profiles measured under storm conditions. * correspond to the value of the higher wave height for the previous six month, associated to the storm profiles.

\begin{tabular}{|c|c|c|c|c|c|}
\hline \multirow[t]{2}{*}{ BEACH } & \multirow{2}{*}{$\begin{array}{c}\text { Monthly averaged } \\
\text { significant height } \mathrm{H}_{\mathrm{s}}(\mathrm{m})\end{array}$} & \multirow{2}{*}{$\begin{array}{l}\text { Peak period } \\
\mathrm{T}_{\mathrm{p}}(\mathrm{s})\end{array}$} & \multirow{2}{*}{$\begin{array}{l}\text { Modal tidal } \\
\text { range (m) }\end{array}$} & \multicolumn{2}{|c|}{$\mathrm{D}_{50}(\mathrm{~mm})$} \\
\hline & & & & Surf profile & Shoaling profile \\
\hline Zumaia & 0.82 & 9.73 & 3.65 & 0.44 & 0.30 \\
\hline Zumaia $(T)$ & $2.56^{*}$ & 12.67 & 3.65 & 0.44 & 0.30 \\
\hline Zarautz & 1.94 & 12.68 & 3.65 & 0.35 & 0.25 \\
\hline Bakio & 0.94 & 9.10 & 3.65 & 0.30 & 0.23 \\
\hline San Lorenzo & 0.80 & 7.41 & 3.25 & 0.34 & 0.25 \\
\hline San Lorenzo $(T)$ & $2.30 *$ & 11.68 & 3.25 & 0.34 & 0.25 \\
\hline Carranques & 0.58 & 8.89 & 3.25 & 0.36 & 0.23 \\
\hline Castilla & 0.63 & 6.95 & 2.65 & 0.35 & 0.20 \\
\hline La Antilla & 0.76 & 9.71 & 2.65 & 0.35 & 0.22 \\
\hline La Barrosa & 0.82 & 8.58 & 2.65 & 0.33 & 0.23 \\
\hline El Vendrell & 0.54 & 6.9 & 0.40 & 0.27 & 0.19 \\
\hline
\end{tabular}

TABLE 2. - Description of the survey parameters of the laboratory profiles measured by Peters et al. (1996).

\begin{tabular}{lccc}
\hline Case & \multicolumn{2}{c}{ Wave parameters } & Water Level \\
& $\mathrm{H}_{\mathrm{mo}}(\mathrm{m})$ & $\mathrm{T}_{\mathrm{p}}(\mathrm{m})$ & \\
\hline 1 & 1.20 & 5 & Constant \\
2 & 1.20 & 10 & Constant \\
3 & 1.10 & 5 & Variable $(1 \mathrm{~m})$ \\
4 & 1.05 & 10 & Variable $(1 \mathrm{~m})$ \\
\hline
\end{tabular}
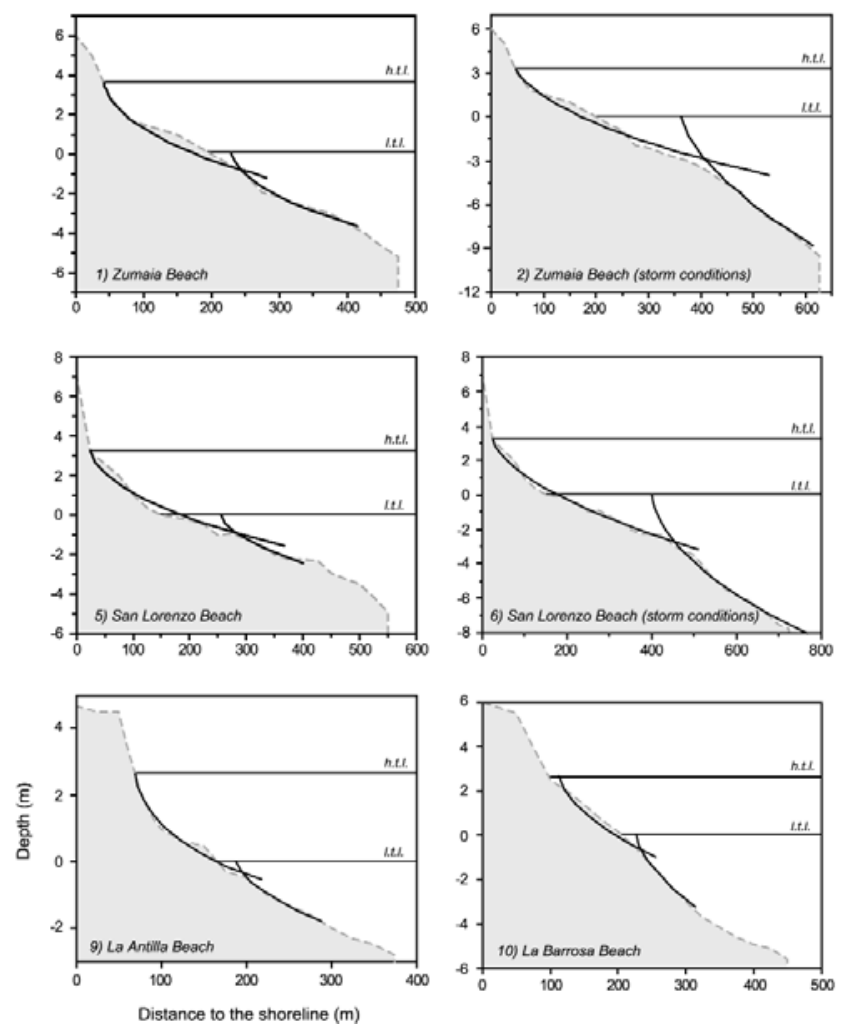
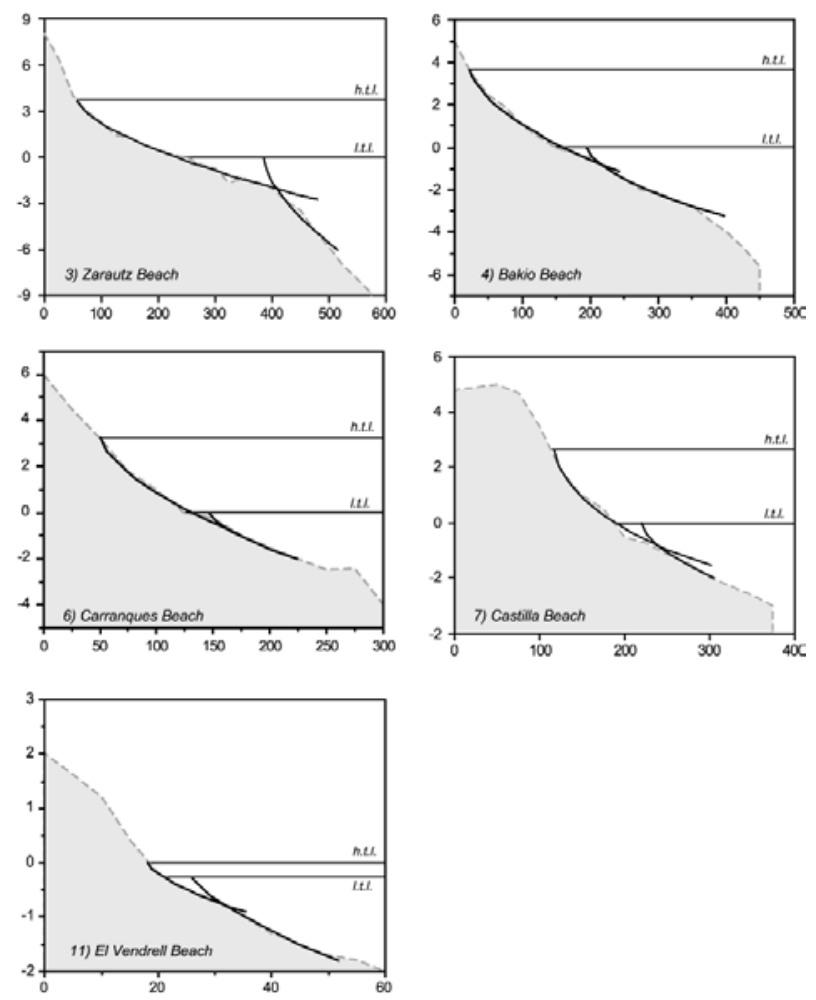

FIG. 5. - Comparison of measured profiles along Spanish coast and the two-section profile formulation: 1. Zumaia Beach; 2. Zumaia beach (under storm conditions); 3. Zarautz Beach; 4. Bakio Beach; 5. San Lorenzo Beach; 6. San Lorenzo beach (under storm conditions); 7. Carranques Beach; 8. La Antilla Beach; 9. Castilla Beach; 10. La Barrosa Beach; 11. El Vendrell Beach. 

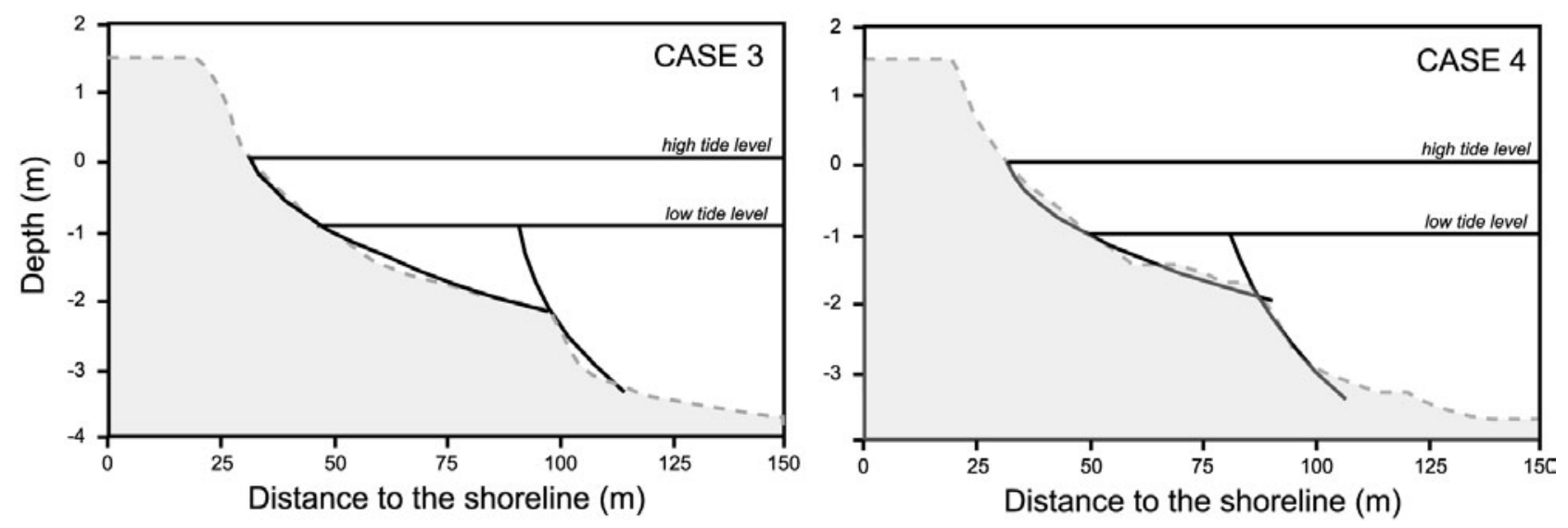

FIG. 6. - Comparison of laboratory profiles (Peters et al., 1996) and the two-section profile formulation: $a$. Case 3, corresponding to $\mathrm{H}=$ $1.10 \mathrm{~m}$ and $\mathrm{T}_{\mathrm{p}}=5 \mathrm{~s} ; b$. Case 4 , corresponding to $\mathrm{H}=1.05 \mathrm{~m}$ and $\mathrm{T}_{\mathrm{p}}=10 \mathrm{~s}$.

hard to achieve, mainly because it is impossible to compare the morphology of the same beach with and without tide directly in nature. However, there are a few laboratory experiments that incorporate a constant change of level as a well constraint variable. In practical terms, for our purpose the influence of the tide was validated using four laboratory surveys measured by Peters et al. (1996). These experiments were performed in the Hannover wave channel with $324 \mathrm{~m}$ length, $5 \mathrm{~m}$ width and $7 \mathrm{~m}$ depth, which was able to generate waves of $2 \mathrm{~m}$ height. Irregular waves were simulated using a TMA spectrum at constant level and at a $1 \mathrm{~m}$ changing level. The median grain size was 0.33 $\mathrm{mm}$. The sinusoidal tidal wave with a 12 hour period was simulated as a step function with increments of $25 \mathrm{~cm}$ each 60 minutes. High and low tide duration were 90 minutes. The survey began at high tide, which coincided with the mean sea level in the surveys without tide $(4.5 \mathrm{~m})$. The conditions for each case are presented in Table 2.

\section{VALIDATION OF THE MODEL AND DISCUSSION}

The two-section equilibrium beach profile proposed was tested against field data measured along the Spanish coast and is able to predict the tidal beach profile with reasonable success. The actual and the simulated profiles are shown in Figure 5. The model was also fitted to laboratory tidal profiles measured by Peters et al. (1996) (Fig. 6). The agreement between the simulated profiles and the actual profiles is good. The fitting (A, B, C, D) and morphological parameters $\left(\mathrm{h}_{\mathrm{r}}\right.$ and $\left.\mathrm{x}_{\mathrm{o}}\right)$ are shown in Table 3 . The model including the tidal influence is described by expressions (1) and (2) and is valid to characterise not only microtidal profiles but also meso- and macrotidal beaches.

The model divides tidal and non-tidal beaches into two sections, corresponding to the surf and shoaling profiles, as a function of the dominant dissipation process. Each section is divided in turn into

TABLE 3. - Fitting coefficients (A, B, C and D) and morphological parameters ( $h_{r}$ and $x_{0}$ ) of the two-section equilibrium profile for tidal beaches.

\begin{tabular}{|c|c|c|c|c|c|c|c|}
\hline \multirow[t]{2}{*}{ BEACHES } & \multicolumn{2}{|c|}{ Surf profile } & \multicolumn{2}{|c|}{ Shoaling profile } & \multirow[t]{2}{*}{$\mathrm{h}_{\mathrm{r}}$} & \multirow[t]{2}{*}{$\mathrm{X}_{\mathrm{o} \text { measured }}$} & \multirow[t]{2}{*}{$\mathrm{X}_{\mathrm{o} \text { calculated }}$} \\
\hline & A & B & $\mathrm{C}$ & $\mathrm{D}$ & & & \\
\hline Zumaia & 0.18 & 0.07 & 0.14 & 0.06 & 0.77 & 188 & 187.41 \\
\hline Zumaia (T) & 0.155 & 0.02 & 0.23 & 0.02 & 2.88 & 321 & 316.06 \\
\hline Zarautz & 0.12 & 0.005 & 0.25 & 0.008 & 2.06 & 326 & 326.41 \\
\hline Bakio & 0.15 & 0.02 & 0.1 & 0.02 & 0.82 & 172 & 169.59 \\
\hline San Lorenzo & 0.13 & 0.05 & 0.1 & 0.06 & 0.95 & 231 & 231.76 \\
\hline San Lorenzo $(T)$ & 0.13 & 0.015 & 0.2 & 0.02 & 2.75 & 375 & 327.04 \\
\hline Carranques & 0.18 & 0.01 & 0.11 & 0.005 & 0.75 & 96 & 95.27 \\
\hline La Barrosa & 0.15 & 0.03 & 0.17 & 0.01 & 0.64 & 114 & 113.77 \\
\hline Castilla & 0.19 & 0.09 & 0.12 & 0.09 & 0.73 & 103 & 101.15 \\
\hline Antilla & 0.2 & 0.2 & 0.1 & 0.08 & 0.32 & 119 & 109.99 \\
\hline El Vendrell & 0.14 & 0.05 & 0.2 & 0.01 & 0.72 & 7.75 & 17.10 \\
\hline Case 3, Peters et al. (1996) & 0.16 & 0.08 & 0.9 & 0.4 & 1.25 & 59 & 64.42 \\
\hline Case 4, Peters et al. (1996) & 0.17 & 0.16 & 0.5 & 0.1 & 0.95 & 49 & 52.91 \\
\hline
\end{tabular}


an upper and a lower part, according to the relationship between the dissipation and reflection phenomena. Each coefficient of the model describes the slope of the two different areas. Coefficients A and $\mathrm{C}$ are directly proportional to the slope of the upper part of the surf and the shoaling profile respectively. Coefficients B and D are inversely related to the slope of the lower part of the surf and the shoaling profile respectively.

Despite the validity of the two-section equilibrium profile as a general model, the application in tidal and non-tidal beaches shows important differences. The main difference resides in the location of the surf profile. In non-tidal beaches the surf profile extends between the mean sea level and the breaker point. In tidal beaches, it spans from the high tide level to the breaker point at low tide level. Obviously, this involves a change in the expression of the parameter $x_{0}$. In the tidal case, $x_{0}$ is the horizontal distance between the beginning of the surf profile and the virtual origin of the shoaling profile over a new reference: the low tide level (Fig. 3). This is reflected in the expression of $\mathrm{x}_{\mathrm{o}}$ where the tidal range is included (Equation (10)). In Figure 7 the parameter $\mathrm{x}_{\mathrm{o}}$ measured on the profile fit is compared against the parameter $\mathrm{x}_{0}$ calculated using expression (10). Coefficients (A, B, C and D) in this expression were calculated using the predictive relationships established by Bernabeu (1999). These express the dependence between the profile coefficients and the characteristic wave climate and grain size of each beach, using the Dean parameter.

This figure shows the goodness of the Equation (10) for predicting this parameter in tidal beaches. The linear fit between them is given for the expression:

$$
\mathrm{x}_{\mathrm{o} \text { calculated }}=0.96 \mathrm{x}_{\mathrm{o} \text { measured }}
$$

Another difference derived from the above is the position of the discontinuity point, which separates the surf and shoaling profiles (Fig. 3). In tidal beaches, this discontinuity always remains submerged below the low tide level at a depth $h_{r}$, which is a function of the wave height at the closure depth of the beach. Figure 8 shows the relationship between these two parameters. The linear fitting obtained shows that the vertical position of the discontinuity point is mainly controlled by waves, and that the tidal influence results in the horizontal displacement associated with the surf profile stretching. However, this trend should be taken with caution as more data

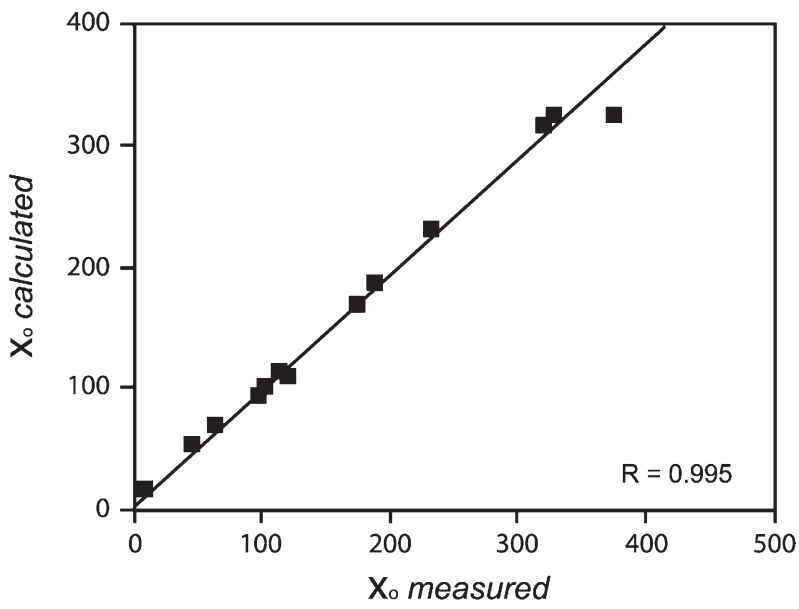

FIG. 7. - Relationship between the parameter $\mathrm{x}_{0}$ directly estimated from the measured profile and calculated with equation (10).

covering the full range of wave heights would be desirable.

Comparison of laboratory profiles with and without tide verified the tidal influence on the beach profile. In both surveys, the wave parameters were nearly constant (the wave height varied slightly, the period was constant). Figure 9 a shows the profiles in an erosive situation (case 1 and 3). The main morphological change between these profiles is that the bar disappears from the profile after the tide is introduced, which supports the results of others authors (Watts and Dearduff, 1954; Hedegaard et al., 1991). In this figure, it is also possible to estimate the lengthening of the surf profile as a response to the tidal range. In this case, the stretching is produced by the erosion of the backshore and by the displacement of the discontinuity point offshore to a deeper location. This displacement is the profile response to

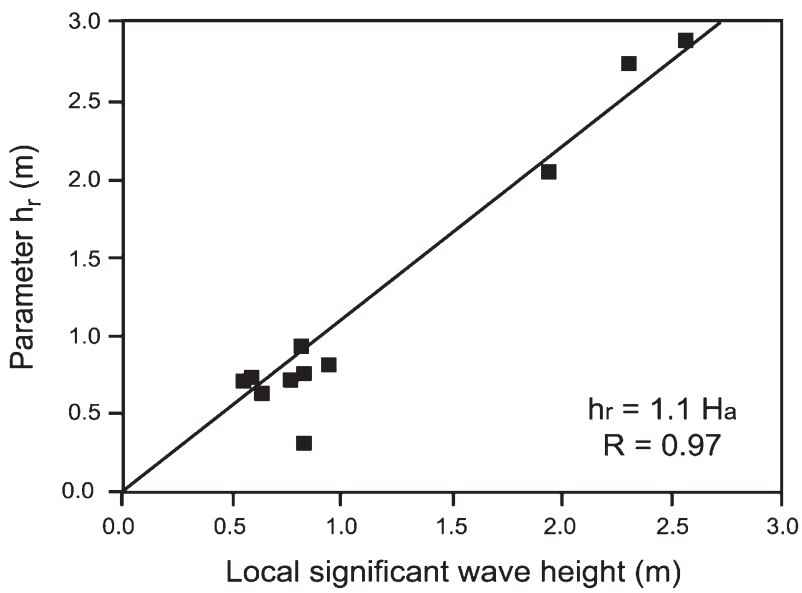

FIG. 8. - Relationship between the discontinuity point depth, $\mathrm{h}_{\mathrm{r}}$, and the low tide level and the wave height that reaches the beach profile in the closure depth. 

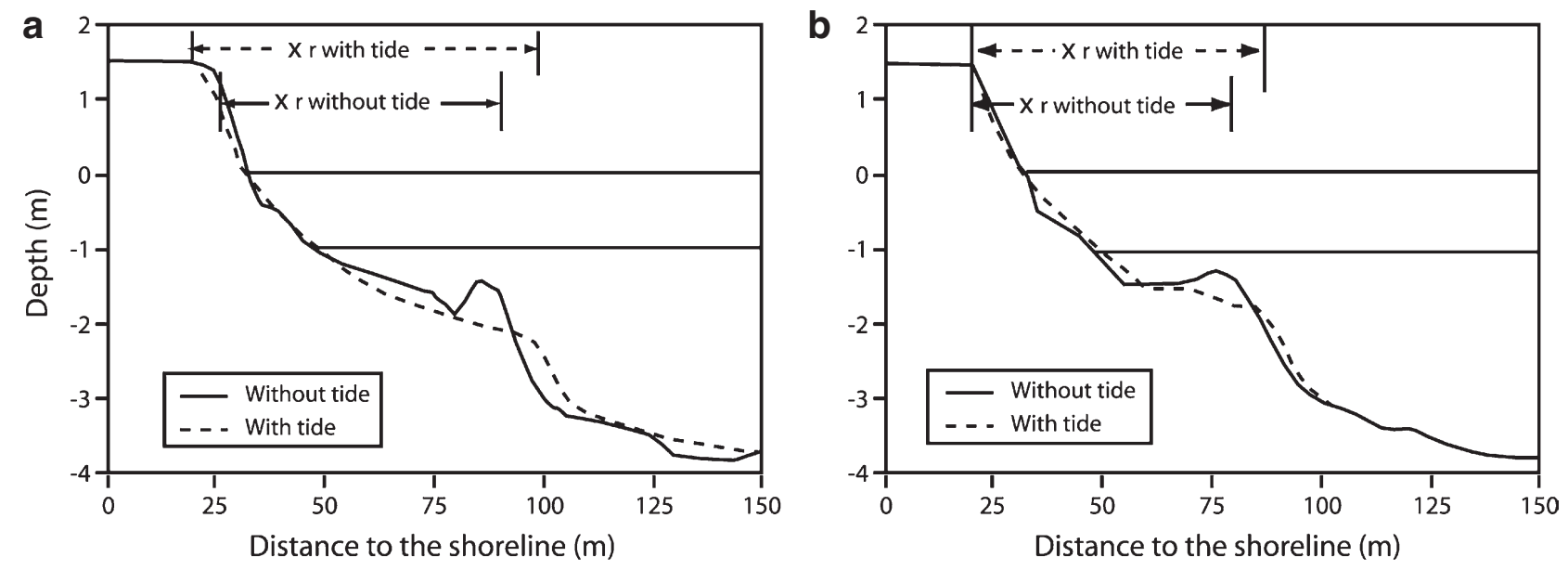

FIG. 9. - Comparison of laboratory profiles with and without tide (Peters et al., 1996): a, case 1 and case 3 , erosive tendency; b, case 2 and case 4 , accumulative tendency.

the forced decrease in water level used to simulate the low tide. The initial mean level in cases 1 and 2 coincides with the high tide level in cases 3 and 4 . The profile response is to maintain the discontinuity point depth $\left(\mathrm{h}_{\mathrm{r}}\right)$ constant with respect to the lowest level of the survey (low tide).

a

REFLECTIVE CASE
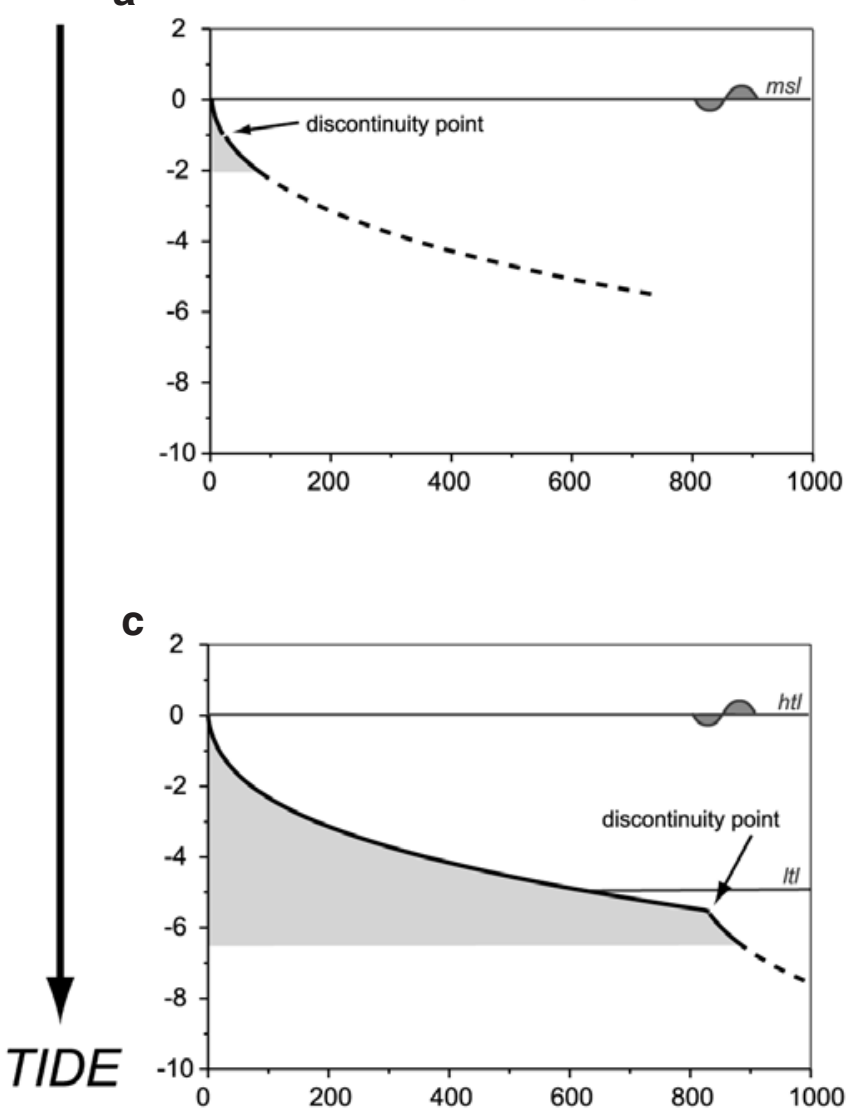

Figure $9 \mathrm{~b}$ compares the profiles with accumulative tendency, cases 2 and 4 . In this situation the lengthening of the surf profile is not so evident. The length increase is relatively small because the two parameters that influence the morphology are modified. On one side the tide tends to stretch the surf

b
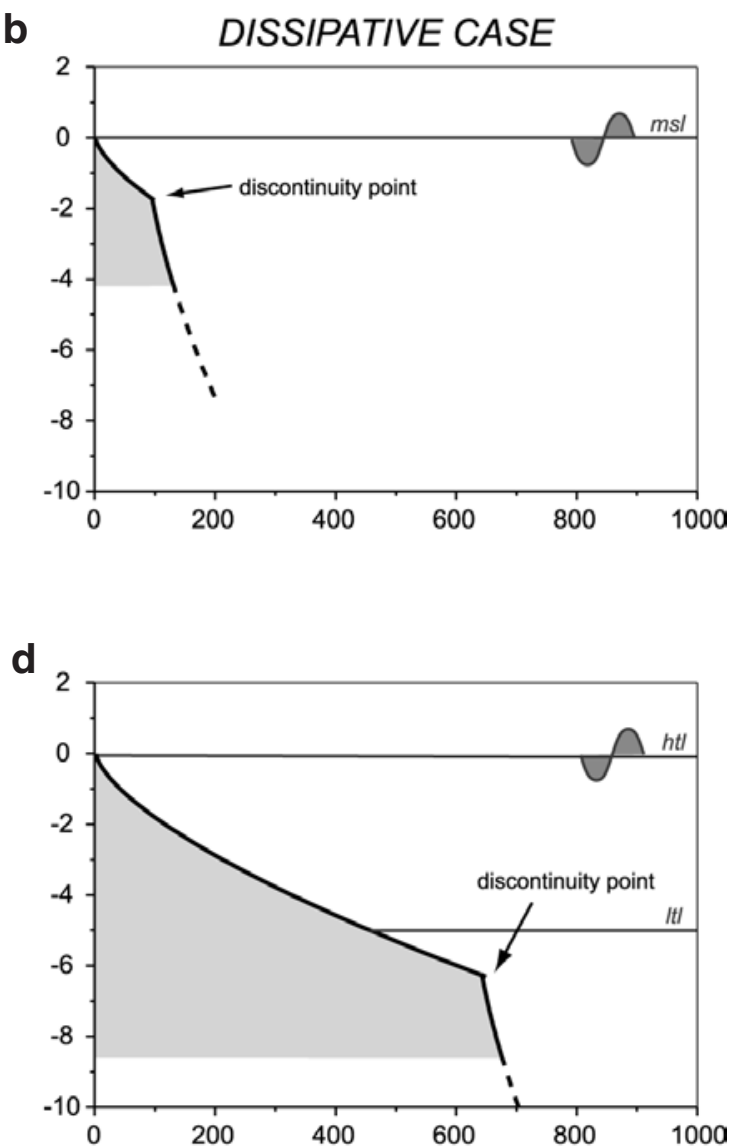

FIG. 10. - Profile morphology predicted from the proposed equilibrium model: a, reflective beaches without tide; b, dissipative beaches without tide; $\mathbf{c}$, reflective beaches with tide and $\mathbf{d}$, dissipative beaches with tide. 
profile. On the other side, the decrease in the wave height forces the discontinuity point to move onshore to a shallower depth and consequently reduces the extension of the surf profile. The opposite effects of the change of tidal range and wave height counteract and are quasi-balanced overall.

The two-section equilibrium profile predicts a reduced surf profile in the upper part and a very flat shoaling profile, in reflective conditions $(\mathrm{H} / \mathrm{wT}<1)$ (Fig. 10a). In contrast, under dissipative conditions $(\mathrm{H} / \mathrm{wT}>6)$ the predicted surf profile is flattened and the shoaling profile is steepened (Fig. 10b). As we deduced in the proposed model after introducing the tide, the shape of the surf and shoaling profiles is maintained, following expressions (1) and (2). Consequently, the values of the four coefficients A, B, C and $\mathrm{D}$ remain constant, and their influence in the profile morphology is preserved. The more evident morphological difference is the lengthening of the surf profile and the displacement of the shoaling profile offshore (Figs. 10c and 10d). This effect is analytically compiled in the expression of the parameter $x_{0}$. As a consequence of this stretching, the surf profile in reflective beaches maintains its steeper upper part whilst lengthening the milder-slope lower part. In tidal beaches, this leads to the development of milder overall slopes in reflective than in dissipative profiles, in contrast to the model of Wright and Short (1984) for microtidal beaches.

\section{CONCLUSIONS}

The equilibrium profile concept is used to analyse the influence of tide on beach morphodynamics. Based on a two-section equilibrium profile, this study concludes that the tidal surf profile comprises from the high tide level to the breaker point at low tide and the shoaling profile offshore of this point. In these cases, the discontinuity point corresponds to the breaker point at low tide.

The level change associated with tide results in the beach profile being exposed to continuously changing hydrodynamical conditions. However, this simple and easy-to-apply model estimates that the wave breaking controls the whole surf profile and that the wave shoaling controls the rest of the profile. Consequently, the main tidal influence on the beach morphodynamics is the lengthening of the surf profile proportionally to the tidal range, which maintains the discontinuity point always submerged.
Despite this tidal effect, the morphology of each section is not modified. Beaches under the same wave and sedimentary conditions, but under a different tidal range, show the same equilibrium profile but a different surf profile length. The two-section formulation proposed by Bernabeu (1999) is valid for micro-, meso- and macrotidal beaches. The parameter $x_{o}$ is the only element in that expression that changes to incorporate the tidal range.

Field and laboratory data testing of the predicted tidal equilibrium profile showed the goodness of this approach.

\section{ACKNOWLEDGEMENTS}

The measured data were kindly provided by the Dirección General de Costas (Ministry of the Environment, Spain). Thanks to J. Guillén and J. A. Jimenez for their constructive reviews. Also thanks to D. Rey for revising the English version of this manuscript. Paper $\mathrm{N}^{\mathrm{o}} 256$ of the Marine Geology Group (EX1) of the University of Vigo. Contribution to projects: REN2000-1102 MAR (C.I.C.Y.T.), and partially to PGIDT00PXI30105PR (Xunta de Galicia), PGIDT00MAR30103PR (Xunta de Galicia) and IGCP 464. R. M. and C. V. acknowledge the financial support received from the European Community through the project $\mathrm{N}^{\circ}$ MAS3-CT97-0081, "Surf and Swash Zone Mechanics" (SASME) and from the C.I.C.Y.T., project AMB99-0543.

\section{REFERENCES}

Bagnold, R.A. - 1940. Beach formation by waves: some model experiments in a wave tank. J. Inst. Civil Engrs., 15: 27-52.

Bernabeu, A.M. - 1999. Desarrollo, validación y aplicaciones de un modelo general de perfil de equilibrio en playas. Ph.D. thesis. Univ. Cantabria.

Bernabeu, A.M., R. Medina, C. Vidal and J.J. Muñoz-Pérez. 2001. Estudio morfológico del perfil de playa: modelo de perfil de equilibrio en dos tramos. Rev. Soc. Geol. España, 14(3-4): 227-236.

Bodge, K. - 1992. Representing equilibrium beach profiles with an exponential expression. J. Coast. Res., 8-1: 47-55.

Bruun, P. - 1954. Coast erosion and the development of beach profiles. Beach Erosion Board, Technical Memorandum, № 44.

Butt, T. and P. Russell. - 2000. Hydrodynamics and cross-shore sediment transport in the swash zone of natural beaches: a review. J. Coast. Res., 16: 255-268.

Davies, J.L. - 1964. A morphogenic approach to world shorelines. Zeitschrift für Geomorphology, 8: 127-142.

Davis, R.A. and M.O. Hayes. - 1984. What is a wave-dominated coast?. Mar. Geol., 60: 313-329.

Dean, R.G. - 1973. Heuristic models of sand transport in the surf zone. Proceedings Conf. in Engineering Dynamics on the Surf Zone, Sydney, N. S. W.: 208-214.

Dean, R.G. - 1977. Equilibrium beach profiles: U.S. Atlantic and Gulf coasts. Department of Civil Engineering, Ocean Engineer- 
ing Report $\mathrm{N}^{\mathrm{o}} 12$, University of Delaware, Newark, Delaware.

Dubois, R.N. - 1972. Inverse relation between foreshore slope and mean grain size as a function of the heavy mineral content Geol. Soc. Am. Bull., 83: 871-876.

Elfrink, B. and T. Baldock. - 2002. Hydrodynamics and sediment transport in the swash zone: a review and perspectives. Coast. Engineer., 45: 149-167.

Fredsoe, J. and R. Deigaard. - 1992. Mechanics of coastal sediment transport. Advanced series on ocean engineering, vol. 3, World Scientific Publishing Co., Singapore.

Gómez-Pina, G. - 1995. Análisis de perfiles de playa en las fachadas cantábrica y atlántica de la costa española y su aplicación a proyectos de regeneración. MsC. Thesis. Univ. Cantabria.

Hedegaard, I.B., R. Deigaard and J. Fredsoe. - 1991. Onshore/offshore sediment transport and morphological modelling of coastal profiles. Proceedings of Coastal Sediments' 91, A.S.C.E.: $643-654$.

Horn, D.P. - 1993. Sediment dynamics on a macrotidal beach: Isle of Man, U.K. J. Coast. Res., 9-1: 189-208.

Inman, D.L., M.H.S. Elwany and S.C. Jenkins. - 1993. Shorerise and Bar-Berm Profiles on Ocean Beaches. J. Geophy. Res. Vol. 98, C10: 18181-18199.

Jago, C.F. and J. Hardisty. - 1984. Sedimentology and morphodynamics of a macrotidal beach, Pendine Sands, SW Wales. Mar. Geol., 60: 123-154.

Kriebel , D.L. and R.C. Dean. - 1985. Numerical simulation of time-dependent beach and dune erosion. Coast. Engineer., 9: 221-245.

Kotvojs, F. and P.J. Cowell. - 1990. Refinement of the Dean profile model for equilibrium beaches profiles. Australian Civil Engineer. Trans., 33: 9-15.

Masselink, G. - 1993. Simulating the effects of tides on beaches morphodynamics. J. Coast. Res., Special Issue 16: 180-197.

Masselink, G. and A.D. Short. - 1993. The effect of tide range on beach morphodynamics and morphology: a conceptual beach model. J. Coast. Res., 9, 3: 785-800.

Masselink, G. and L. Li. - 2001. The role of swash infiltration in determining the beachface gradient: a numerical study. Mar. Geol., 176: 139-156.

Medina, R., A.M. Bernabeu, C. Vidal and E.M. González. - 2000. Relationships between beach morphodynamics and equilibrium profiles. Proceedings of the 27th Int. Coastal Engineering Conf., A.S.C.E.: 2589-2601.

M.O.P.T. - 1992. Recomendaciones para obras marítimas, ROM 0.3-91 Oleaje. Anejo I: Clima Marítimo en el Litoral Español. Dirección General de Puertos.

Muñoz-Pérez, J.J., L. Tejedor and R. Medina. - 1999. Equilibrium beach profile model for reef-protected beaches. J. Coast. Res., 15, 4: 950-957.

Peters, K., J. Newe and H-H. Dette. - 1996. Development of underwater beach profile by monochromatic and random waves. Proceedings of the 26th Int. Coastal Engineering Conf., A.S.C.E.: 3442-3452.

Swain, S. - 1989. Beach profile development. In: Lakhan, V.C. and Trenhaile, A.S. (eds.), Applications in Coastal Modeling. Pp. 215-232. Elsevier, Amsterdam.

Swart, D.H. - 1974. A schematization of onshore-offshore transport. Proceedings of the 14th Int. Coastal Engineering Conf., A.S.C.E.: $884-900$.

Watts, G.M and R.F. Dearduff. - 1954. Laboratory study of the effect of tidal action on wave-formed beach profile. U.S. Army Corps of Engineers, Beach Erosion Board Tech. Memory 52.

Wright, L.D., R.T. Guza and A.D. Short. - 1982. Dynamics of high energy dissipative surf zone. Mar. Geol., 45: 41-62.

Wright, L.D., and A. D. Short. - 1984. Morphodynamic variability of surf zones and beaches. Mar. Geol., 56: 93-118.

Scient. ed.: A. Palanques 